\title{
Metazoan oocyte and early embryo development program: a progression through translation regulatory cascades
}

\author{
Shobha Vasudevan, ${ }^{1,3}$ Emre Seli, ${ }^{2,3}$ and Joan A. Steitz ${ }^{1,4}$ \\ ${ }^{1}$ Department of Molecular Biophysics and Biochemistry, and Howard Hughes Medical Institute, ${ }^{2}$ Department of Obstetrics \\ and Gynecology, Yale University School of Medicine, New Haven, Connecticut 06536, USA
}

All metazoans that reproduce sexually have the ability to form gametes. The two types of gametes, the egg and the sperm, arise from germ cells, undergo extensive differentiation, and are destined to unite. The outcome of their union, the zygote, maintains and propagates the characteristics of the species. The zygote inherits from the egg not only genetic material but also its cytoplasm, which supports the development of the early embryo through precise expression patterns of maternally inherited messages. The hierarchical organization of these translation regulatory mechanisms is unveiled in the report by Padmanabhan and Richter (2006) in this issue of Genes \& Development.

Mechanisms for establishing the germline and carrying out oogenesis in evolutionarily distant animals exhibit certain common themes. Gametes develop from primordial germ cells (PGC) that are set aside during early embryogenesis (Matova and Cooley 2001). In most metazoans, PGCs have an extragonadal origin and migrate to reach the somatic gonad, where they proliferate by mitosis to form oocytes in females (Matova and Cooley 2001). Oocytes, in turn, enter meiosis, only to be arrested at the prophase of the first meiotic division (Sagata 1996). This first meiotic arrest may last up to a few years in Xenopus or several decades in humans, and is characterized by synthesis and storage of large quantities of dormant mRNA (LaMarca et al. 1973; Rodman and Bachvarova 1976). When later translated, these maternal mRNAs drive the oocyte's re-entry into meiosis/Gebauer et al. 1994; Stebbins-Boaz et al. 1996; Mendez et al. 2000) and control the rate of mitosis during the cleavage divisions after fertilization (Groisman et al. 2000; Oh et al. 2000; Uto and Sagata 2000).

The resumption of meiosis marks the onset of oocyte maturation and is stimulated by progesterone in Xenopus (Bayaa et al. 2000; Tian et al. 2000) and by gonadotropins in mouse and human (Faiman and Ryan 1967;

\footnotetext{
${ }^{3}$ These authors contributed equally to this work.

${ }^{4}$ Corresponding author.

E-MAIL joan.steitz@yale.edu; FAX (203) 624-8213.

Article and publication are at http://www.genesdev.org/cgi/doi/10.1101/ gad.1398906.
}

Rao et al. 1974). In almost all vertebrates, nuclear and cytoplasmic changes associated with oocyte maturation are completed by the metaphase of the second meiotic division, when oocytes become arrested for a second time and await fertilization (Sagata 1996). A complex network of translational activation and repression of stored maternal mRNAs accompanies oocyte maturation (Gebauer et al. 1994; Stebbins-Boaz et al. 1996; Mendez et al. 2000; Oh et al. 2000), while transcription is limited at best.

The transcriptional silencing that begins with oocyte maturation persists during the initial mitotic divisions of the embryo, which, unlike any other, lack an appreciable G1 or G2 phase. In Xenopus, after 12 rapid synchronous cleavages, when the developing embryo is composed of $\sim 4000$ cells, the mid-blastula transition occurs and is characterized by lengthening of the cell cycle, inclusion of G1 and G2, and activation of zygotic transcription (Newport and Kirschner 1982a,b). In mouse and human, induction of transcription in the embryo occurs at the two-cell, and four- to eight-cell stages, respectively (Clegg and Piko 1982; Flach et al. 1982; Braude et al. 1988). Despite the earlier occurrence of zygotic transcription, activation of maternally inherited mRNAs in mammals seems to use translation mechanisms similar to those in other vertebrates (Richter 1999; Oh et al. 2000).

On a molecular level, it is known that meiotic reactivation is initiated by translation of specific maternal messages such as those encoding rapid inducer of G2/M progression in oocytes/Speedy (RINGO/Spy), cyclin B1, and cyclin-dependent protein kinase 2 (Cdk2) (Ferby et al. 1999; Mendez and Richter 2001; Eichenlaub-Ritter and Peschke 2002; Dekel 2005). Translation of the RINGO/Spy message is essential since the RINGO/Spy protein, a novel cell cycle regulator with unique kinasebinding and activation domains, is required to activate Cdk2 (Ferby et al. 1999; Lenormand et al. 1999; Terret et al. 2001; Cheng et al. 2005). The subsequent action of these gene products is followed by Aurora A/Eg2 protein kinase activation, which, in turn, promotes polyadenylation of specific transcripts including that of mos serine/ threonine kinase (Fig. 1, see orange boxes). Mos is essen- 
tial as it activates a mitogen-activated protein kinase (MAPK) cascade that enables progression through oocyte maturation, maintains activation of a maturation-promoting complex, and is an important component of the cytostatic factor that arrests the matured egg in metaphase II to await fertilization (for review, see Castro et al. 2001; Gandolfi and Gandolfi 2001; Dekel 2005).

The best-studied mechanism regulating the translation of maternally derived mRNAs in the oocyte cytoplasm is polyadenylation. Not only is polyadenylation a nuclear processing event that fashions the 3 '-end of almost all pre-mRNAs (Manley 1995; Wahle 1995), but it also takes place in the cytoplasm during oocyte maturation and early embryo development. Several 3'-untranslated region (UTR) motifs have been implicated in the regulation of polyadenylation of maternal mRNAs (Eichenlaub-Ritter and Peschke 2002). These include the cytoplasmic polyadenylation element (CPE), the $\mathrm{Pu}-$ milio-binding element (PBE), and the embryonic deadenylation element (Gray and Wickens 1998). Additional control mechanisms involving AU-rich elements or microRNAs may also contribute either directly or in concert with the above elements (de Moor et al. 2005; Piccioni et al. 2005).

The article by Padmanabhan and Richter (2006) not only establishes RINGO/Spy as an early inducer of CPEmediated translation following oocyte activation in Xenopus, but also suggests the presence of a regulatory cascade involving multiple mechanisms acting upon distinct $3^{\prime}$-UTRs to control the expression of maternal mRNAs in the oocyte. A predominant theme that emerges is the regulation of the regulators themselves; through an integration of successive translation control mechanisms, with one leading to regulation of the next, temporally precise consequences are generated that correlate with succeeding stages of the developmental program.
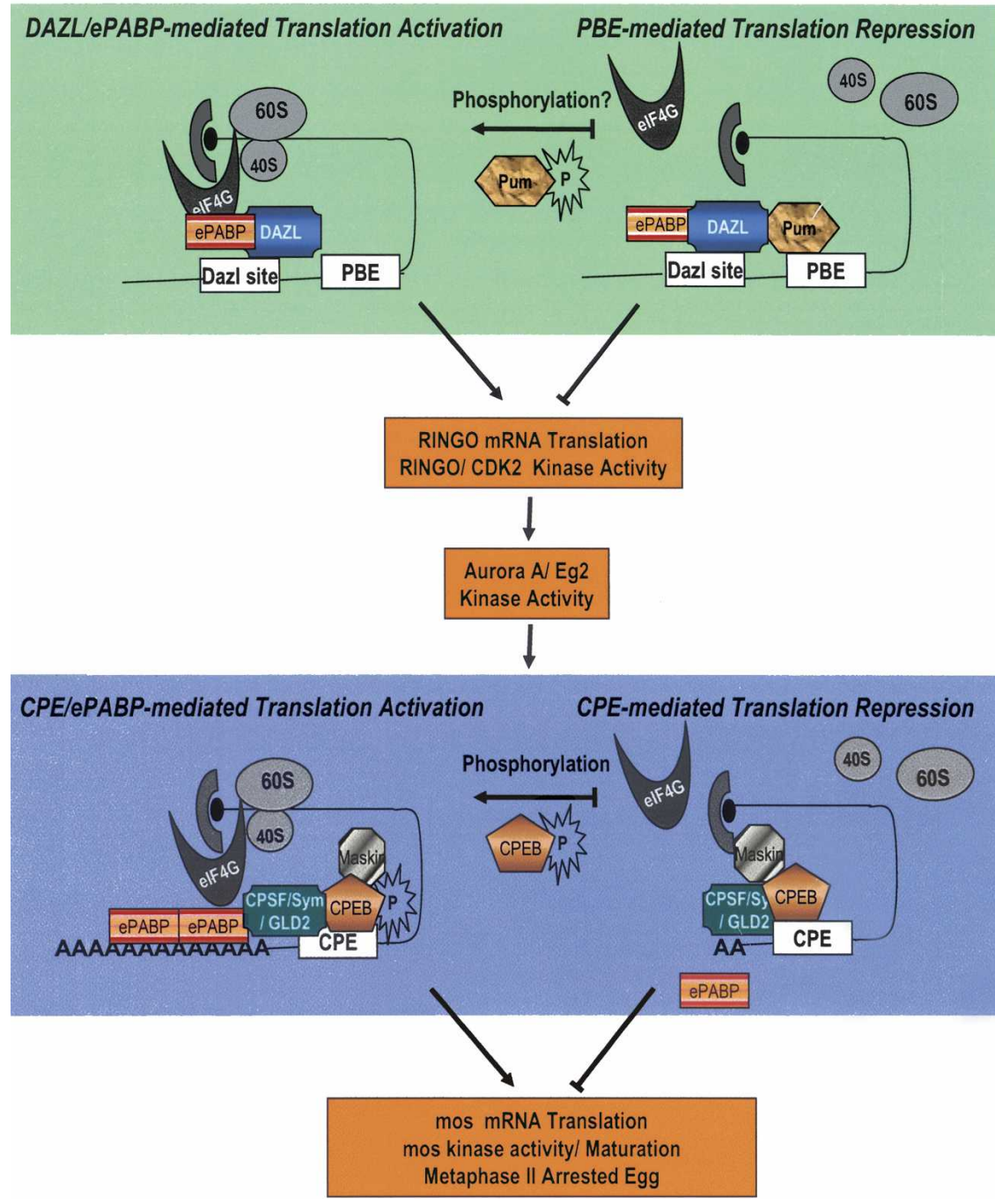

Figure 1. Maternal mRNA translation progresses through a tightly controlled cascade of translation regulatory mechanisms. Maternal mRNAs are regulated by $3^{\prime}$-UTR elements that serve to activate or repress through a hierarchical series of successive translation regulatory mechanisms. In the G2-arrested prophase I oocyte, meiotic reactivation occurs in response to signals such as progesterone. As shown in the green box, this causes loss of Pumilio 2 binding to the PBE and alleviation of Pumilio 2-mediated translation repression of PBE-bearing transcripts. Recruitment of DAZL/ePABP to such a PBEbearing message, as in the case of the RINGO/Spy mRNA, throws the translational switch through interaction with the eIF4G cap-binding complex. Activity of the RINGO/Spy protein then leads (presumably via activation of the Aurora $\mathrm{A} / \mathrm{Eg} 2$ protein kinase) to subsequent activation of $\mathrm{CPEB}$, which initiates the next wave of translation regulation as shown in the blue box. CPE-mediated translation repression is imposed by maskin, which binds CPEB and prevents eIF4G association with the cap. CPEB activation by phosphorylation leads to remodeling and activation of the CPEB/CPSF/Symplekin/ GLD2 complex, resulting in polyadenylation and recruitment of ePABP, which alleviates CPE-mediated translation repression. Translational activation of messages such as mos protein kinase then permits succeeding steps in maturation, culminating in mos-mediated metaphase II arrest of the mature egg. (The cap and cap-binding eIF4E protein are depicted as a black circle and a semicircle, respectively; 40S and 60S are ribosomal subunits, while Sym depicts Symplekin.) 


\section{Cytoplasmic polyadenylation}

CPEs (Mendez and Richter 2001), are U-rich sequences in the 3'-UTRs of maternal mRNAs that can either recruit a translation-repressive complex or direct active polyadenylation and resumption of translation (Fig. 1, see blue box). Both activities are dependent on a key RNA-binding protein called CPE-binding protein (CPEB). $\mathrm{CPEB}$ engages a repressor called maskin, which blocks cap-dependent translation. Additionally, during meiotic maturation, CPEB phosphorylation leads to activation of a CPEB-associated poly(A) polymerase complex, which contains cleavage and polyadenylation specificity factor (CPSF), Symplekin, and the poly(A) polymerase germline development deficient (GLD2), which then elongates the short poly(A) tail of CPE-containing messages (Barnard et al. 2004). The longer poly(A) tail binds poly(A)-binding protein $(\mathrm{PABP})$, which brings in the eukaryotic initiation factor 4G (eIF4G) to replace maskin in the repressive maskin-cap complex interaction, resulting in increased translation. The switch between the repressed and active states requires the phosphorylation of $\mathrm{CPEB}$, as well as the removal of the repressive factor, maskin.

The CPE pathway is highly networked with the phosphorylation and activation of CPEB coupled to feedback control exerted by the products of CPE-containing messages on several levels. Indeed, the mRNA that encodes the Aurora A/Eg2 kinase (see Fig. 1) required for CPEB activation is itself a CPE-containing message.

The CPE pathway uses additional mechanisms to provide temporally and spatially regulated translation (Wickens 1990; Bouvet et al. 1994; Stebbins-Boaz and Richter 1994). In G2-arrested mouse oocytes, CPE messages undergo CPE-directed deadenylation, reducing their poly(A) tail lengths to 20-40 nucleotides (nt); this limits their translatability (Huarte et al. 1992; Paynton and Bachvarova 1994). The Drosophila CPEB (called Orb) is a critical regulator of anterior-posterior patterning and germline differentiation that acts through a similar cytoplasmic polyadenylation mechanism with the added complexity of spatial control (Chang et al. 2001; Castagnetti and Ephrussi 2003). In rat hippocampal neurons, CPEB directs transportation of translationally repressed CPE-bearing messages to dendritic synapses where they are activated (Huang et al. 2003). The human ortholog, hCPEB, has been found to localize in stress granules and direct messages to $\mathrm{P}$ bodies, thereby sequestering them from translation (Wilczynska et al. 2005). Therefore, the CPEB/CPE complex may classify messages for translational repression or activation via localization.

\section{Poly(A)-dependent translation control}

The role of the polyadenylation process and resulting poly(A) tail in maternal mRNA gene expression is crucial, dictating either deadenylation or translation (Jackson and Standart 1990; Wormington et al. 1996; Richter 1999). Interestingly, there is no decay of Xenopus messages following deadenylation through oocyte maturation or in the early stages of embryo development (until the mid-blastula transition), suggesting a reversible regu- latory process that can shift mRNAs between repressed and translationally active states (Audic et al. 1997; Voeltz and Steitz 1998). Tethering of poly(A) polymerase leads to premature activation of translation of such messages (Dickson et al. 2001; Rouhana et al. 2005). Thus, either the act of polyadenylation and/or the poly(A) tail itself is critical for meiotic activation and subsequent maturation-dependent translation of CPE-containing messages.

In clear contrast, during early oogenesis prior to meiotic arrest, many non-CPE messages remain fully polyadenylated and are translated. However, following meiotic reactivation, these messages are specifically deadenylated by a maturation-activated deadenylase that is released from the nucleus upon germinal vesicle (nucleus) breakdown, thereby repressing their translation and promoting the translation of CPE-bearing transcripts (Wickens 1990; Wormington 1993).

There are at least three possible polyadenylationlinked mechanisms that could individually or cooperatively function to activate translation. First, since the process of polyadenylation itself appears to impact posttranscriptional processes-reminiscent of the role of nuclear history in dictating downstream events in the life of an mRNA (for review, see Moore 2005) - the polyadenylation machinery may modify or load a factor conducive for translation. Richter and colleagues have suggested that 2 '-O-ribose methylation of the $5^{\prime}$-cap of the mRNA may be such a modification, but how the cytoplasmic poly(A) polymerase complex would orchestrate cap methylation remains mysterious (Mendez and Richter 2001). Second, a translationally negative complex formed on a partially deadenylated message may simply be overridden by extension of a short poly(A) tail. Earlier, Richter's group demonstrated that maskin is tethered by such a 3 '-end in a way that prevents the cap-binding protein eIF4E from forming a complex with eIF4G, a normal requirement for ribosome recruitment and translation (Cao and Richter 2002; Groisman et al. 2002). Third, extension of the poly(A) tail may relocate the message from repressed bodies to the translation apparatus through recruitment of PABP (Brengues et al. 2005; Kedersha et al. 2005).

\section{Polyadenylation-independent translational control}

It has become increasingly evident that mechanisms distinct from cytoplasmic polyadenylation are required in parallel with CPE regulation to control Xenopus gene expression in a transcript-specific and temporal manner (de Moor et al. 2005; Piccioni et al. 2005). As revealed in the article by Padmanabhan and Richter (2006), such processes can also occur prior to and be required for activation of the subsequent CPE translation control mechanism (see Fig. 1).

Padmanabhan and Richter (2006) have found a second important 3'-UTR element, the PBE, in the Xenopus RINGO/Spy mRNA. The PBE is a defined binding site for certain members of the Pumilio family of proteins (White et al. 2001; Fox et al. 2005). Previously, in Dro- 
sophila embryos, Pumilio had been shown to bind a $3^{\prime}$ UTR element dubbed the Nanos regulatory element (NRE) and interact with another repressor, Nanos, in Drosophila embryos to prevent the translation of hunchback mRNA (Zamore et al. 1997; Wharton et al. 1998). Pumilio 2 binding to the PBE likewise effects translation repression of the RINGO/Spy mRNA through the participation of two other RNA-binding proteins, deleted in azoospermia (DAZ)-like protein (DAZL) and embryonic PABP (ePABP). Whether the process involves active deadenylation, as is known for some Pumilio orthologs (Wickens et al. 2002), or instead builds a repressed mRNP complex independent of the poly(A) tail, the case for other Pumilio proteins (Chagnovich and Lehmann 2001), is not yet clear. In fact, the poly(A) status of the RINGO/Spy message at this stage of development has not been established. Since artificial tethering of DAZL and ePABP was previously shown to lead to significant translation activation independent of any signaling or without a poly(A) tail (Collier et al. 2005), it seems more likely that Pumilio 2 recruits a repressive complex to the RINGO/Spy mRNA or alters the mRNP to prevent translation. Indeed, overexpression of the $\mathrm{N}$ terminus of Pumilio 2 titrates away the inhibition, suggesting the existence of a cofactor for repression (Padmanabhan and Richter 2006). As is the case for CPEB (see above), data on the yeast Pumilio homolog Puf6 suggest that repression may be localization mediated (Gu et al. 2004); bound transcripts become sequestered in translationally silenced complexes reminiscent of stress granules of mammalian cells (Brengues et al. 2005; Kedersha et al. 2005).

\section{Temporal precision by a synergistic mechanism}

The above pathways collaborate to provide temporal precision as well as substrate specificity to the sequential translation of different maternal transcripts in the Xenopus oocyte (see Fig. 1). The PBE-containing RINGO/Spy message is repressed by Pumilio 2 in conjunction with DAZL and ePABP, as demonstrated in the Padmanabhan and Richter (2006) article. Upon meiotic reactivation, Pumilio 2 loses its interactions with both the PBE and the DAZL and ePABP proteins, permitting the DAZL/ ePABP complex to activate translation either independently or through additional unidentified cofactors (Fig. 1, green box). RINGO/Spy is then expressed, leading to activation of CPEB by phosphorylation, which, in turn, elicits polyadenylation and translation activation of the mRNA for a critical oocyte maturation factor, the mos kinase (Fig. 1, blue box).

A defining feature of this regulatory network is the presence of a DAZL-binding site on the same transcript as the PBE. The interplay between these two translational control elements orchestrates precise translation of the RINGO/Spy mRNA (Padmanabhan and Richter 2006). DAZL binds to a consensus sequence with a GUUC/U-rich core (Jiao et al. 2002; Maegawa et al. 2002; Fox et al. 2005), and apparently recruits ePABP/PABP to the mRNA (Collier et al. 2005). Yet, this translation- activating component is subject to the overriding dominance of PBE-bound Pumilio 2, which enforces translational repression. Upon meiotic reactivation, Pumilio 2 loses its affinity for the PBE and for DAZL, but DAZL and $\mathrm{ePABP}$ remain bound to the mRNA (Fig. 1, green box). Therefore, the specificity of maternal transcript translation is imparted by which regulators recognize the message and when each regulator is active as a consequence of a preceding translation regulation event.

Meanwhile, other CPE-bearing transcripts, such as cyclin B1 mRNA, are additionally repressed through an $\mathrm{xPumilio}$ site $(\mathrm{xPB})$ that recruits a different Pumilio homolog (Nakahata et al. 2003). In this case, selective temporal control is imposed on cyclin B1 mRNA expression through a two-pronged effect on translation. First, cyclin B1 mRNA is repressed predominantly by the CPEB mechanism discussed earlier (Cao and Richter 2002). Second, xPumilio can interact with CPEB through its PUF RNA-binding motif and may thereby impose an additional constraint on CPEB-mediated translation regulation (Nakahata et al. 2003). This limitation may involve a mechanism similar to the one discovered by Padmanabhan and Richter (2006), where xPumilio bound to the $\mathrm{XPB}$ site interacts in cis with additional $3^{\prime}$-UTR element regulatory complexes such as CPEB or DAZL/ ePABP (Moore et al. 2003; Nakahata et al. 2003). Repression of cyclin B1 mRNA is released upon maturation through activation of CPEB and loss of xPumilio binding to the mRNA and to $\mathrm{CPEB}$; as a consequence, translation proceeds through a CPE-mediated polyadenylation mechanism where loss of repression requires ePABP recruitment (Cao and Richter 2002; Nakahata et al. 2003). This regulation does not affect non-CPE messages or the CPE-only messages. Rather, the presence of both a CPE and an $\mathrm{XPB}$ site in certain transcripts or of a DAZL site and a $\mathrm{PBE}$ site on others could impart a highly precise temporal order of expression in a transcript-specific manner. Consequently, translation activation of messages with one element such as that of the CPE-bearing mos would precede those with additional elements, as in cyclin B1. This scenario suggests that the RNA-binding protein players-Pumilio, DAZL, and CPEB, which can individually function as translation regulators-reassociate with each other to form multiple transcript-specified combinations. They thereby achieve a more refined translational control, although using a common ePABP/ PABP complex.

\section{ePABP: a common translation effector}

ePABP is a distinctive member of an evolutionarily conserved family of PABPs. PABPs are present from yeast to humans and play vital roles in mRNA metabolism, through biogenesis, localization, translation, and turnover of mRNAs (Mangus et al. 2003; Kuhn and Wahle 2004). These RNA-binding proteins have very high affinity for homopolymeric poly(A) tracts and bear one or four RNA recognition motifs (RRMs), as well as a conserved C-terminal region with a PABP signature motif (see Fig. 2). 
Figure 2. Schematic representation of four key RNA-binding proteins involved in the regulation of maternal mRNA translation in oocytes. Domain structures and known interacting regions for CPEB (Mendez and Richter 2001), ePABP/PABP1 (Seli et al. 2005), DAZL (Moore et al. 2003; Collier et al. 2005), and Pumilio (Wharton et al. 1998) are shown. The structure for ePABP/PABP1 is shared by all cytoplasmic PABPs, whereas nuclear PABPs contain one RRM (Mangus et al. 2003). Pumilio-2 belongs to the PUF family (Pum [Pumilio] and FBF [fem-3 mRNA-binding factor]), characterized by a highly conserved C-terminal RNA-binding domain, composed of eight tandem repeats (Spassov and Jurecic 2003a).
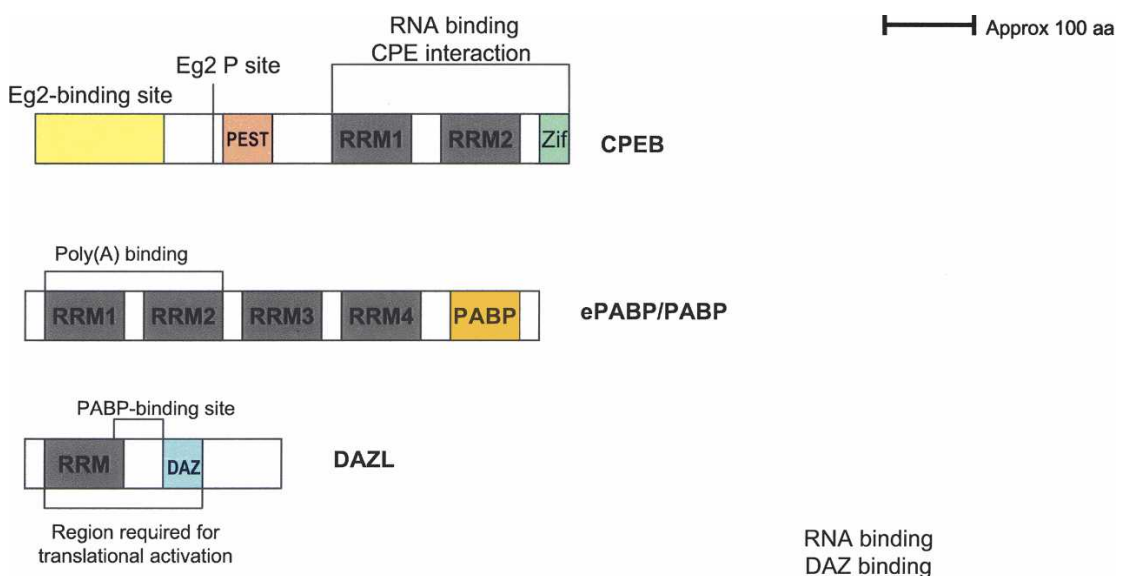

RNA binding DAZ binding

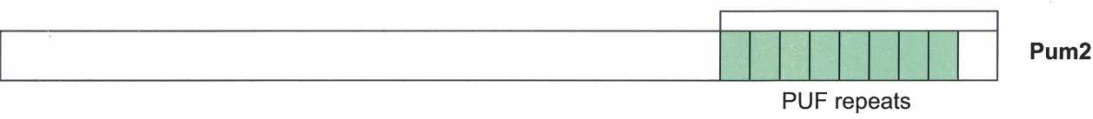

ePABP has been characterized in Xenopus and mouse (Voeltz et al. 2001; Seli et al. 2005) and is $~ 70 \%$ identical at the amino acid level to classical PABP, with the most marked differences near the $\mathrm{C}$ terminus. Since this region is essential for interaction with $\mathrm{PABP}$-specific regulators that can modulate function, truncation as well as variations in the $\mathrm{C}$-terminal region of $\mathrm{ePABP}$ relative to PABP may define novel roles. Yet, PABP and $\mathrm{ePABP}$ have been demonstrated to be interchangeable for many PABP functions, including rescue of a pab1s lethality in Saccharomyces cerevisiae, interactions with the cap-binding eIF4G complex, and with termination factor eRF3, poly(A), and AU-rich element binding, as well as preventing deadenylation of the mRNA (Voeltz et al. 2001; Cao and Richter 2002; Cosson et al. 2002). A feature that distinguishes ePABP from the normal cytoplasmic PABP is its expression pattern: ePABP has so far been found to be expressed exclusively in an oocyte- and embryo-specific manner (Voeltz et al. 2001; Seli et al. 2005). The realization that ePABP is the predominant $\mathrm{PABP}$ present during oocyte maturation and early embryogenesis in both Xenopus and mouse begs the question of how it may function differently from cytoplasmic PABP, which replaces it later in development.

The Padmanabhan and Richter (2006) article describes a new role for ePABP in controlling translation of an upstream regulator of CPEB upon meiotic activation and subsequent maturation. Since the modulation of translation of the RINGO/Spy mRNA through the PBE operates in the absence of CPEB, ePABP appears to be involved in a novel cytoplasmic polyadenylation-independent process. Previous data with a tethering system indicated that DAZL or ePABP itself is sufficient to promote translation of a reporter in Xenopus oocytes (Collier et al. 2005; Wilkie et al. 2005). Here it may be significant that ePABP was originally identified not as a PABP but through its direct interaction with an AU-rich upstream sequence in the 3'-UTR (Voeltz et al. 2001). Since tethering a mutant DAZL lacking its ePABP-bind- ing domain was unable to stimulate translation /Collier et al. 2005), a key function of DAZL may be to bind and coordinate $\mathrm{PABP}$ with negative translation regulators bound to the 3'-UTR of the message. One such negative regulator, the Pumilio/PBE complex, functions to repress translation, presumably through its interactions with the DAZL/ePABP complex (Fig. 1, green box; Moore et al. 2003; Padmanabhan and Richter 2006). Conversely, in the absence of negative elements such as the PBE, as in Figure 3 of the article by Padmanabhan and Richter (2006), translation was activated without a need for meiotic activation or subsequent maturation signals. Therefore, the Padmanabhan and Richter data suggest a model in which an adaptive ePABP complex is the key switch that allows oscillation between repressed and translationally active states.

In all these processes, whether polyadenylation dependent or independent, ePABP/PABP plays a critical role by promoting protection of the transcript from deadenylation and in enhancing translation (Voeltz et al. 2001; Wilkie et al. 2005). Tethering ePABP and also cytoplasmic PABP to a reporter stimulated translation in immature oocytes by eightfold (Wilkie et al. 2005), suggesting that both proteins can up-regulate translation. It is also possible that an additional factor contributes to ePABPmediated translation or that ePABP undergoes modification upon meiotic activation and subsequent maturation. In Spisula embryogenesis, PABP is somehow masked in maturing oocytes and unable to bind polyadenylated RNA, revealing the existence of regulatory mechanisms operating on this class of proteins (de Melo Neto et al. 2000). Accordingly, PABP overexpression prevented maturation-dependent deadenylation and translation inactivation of maternal transcripts but did not interfere with CPE-mediated polyadenylation (Wormington et al. 1996). Since ePABP is replaced by increasing levels of PABP in later stages of development after zygotic gene activation (Voeltz et al. 2001; Seli et al. 2005), this programmed substitution of the universal translation effector is likely pivotal for guiding further specifi- 
cation toward a distinct maturation-controlled gene expression program.

\section{DAZL, lessons from different species}

The other RNA-binding protein that the article by Padmanabhan and Richter (2006) sheds new light on is DAZL. Unlike Pumilio, CBEB, and ePABP, which were characterized in studies of model developmental organisms, our knowledge of DAZL originated in human disease.

DAZL was first identified by its homology to DAZ, a gene on the long arm of the Y chromosome that is frequently deleted in infertile men with nonobstructive azoospermia. DAZL and BOULE, two autosomal homologs of DAZ, exist in numerous species. BOULE is considered the ancestor of the DAZ family, with orthologs in Caenorhabditis elegans, Drosophila, mice, and humans (Eberhart et al. 1996; Karashima et al. 2000; Xu et al. 2001). DAZL orthologs are found in vertebrates only, while DAZ genes are restricted to old world monkeys and humans, suggesting that DAZL gave rise to DAZ during primate evolution.

The DAZ/DAZL/BOULE family of proteins is characterized by its nearly exclusive expression in germ cells and by a highly conserved RRM and unique DAZ repeat of 24 amino acids. Both BOULE and DAZL are singlecopy genes that contain only one DAZ repeat (see Fig. 2), whereas most men possess four DAZ genes with one to three RRMs and seven to $24 \mathrm{DAZ}$ repeats.

Despite the similarities in structure and expression patterns among DAZ/DAZL/BOULE family members, the impact of their absence on germ cell maturation varies between species. In Drosophila, Boule expression is limited to males and its loss results in azoospermia because of a defect in the G2/M transition (Eberhart et al. 1996). Conversely, in C. elegans, loss of the single DAZ homolog Daz-1 results in a block at the pachytene stage of meiosis I in oocytes but does not affect spermatogenesis (Karashima et al. 2000). In Xenopus, the DAZ-like gene (Xdazl) is expressed in adult Xenopus ovary and testis but not in any of the somatic tissues (Houston and King 2000); it appears to play a critical role in the development of PGCs (Houston and King 2000). In the mouse (a species that does not have a DAZ gene on the Y chromosome), Dazl expression is limited to germ cells in gonads (Cooke et al. 1996), and targeted disruption of Dazl results in infertility in both males and females (Ruggiu et al. 1997). In the Dazl knockout mouse, both male and female germ cells are lost before the first meiotic arrest (Saunders et al. 2003) despite the fact that these mice contain a functional Boule gene. This is probably because Boule expression in mouse testes does not start until after germ cell development has already been impaired in the Dazl knockout mouse. Interestingly, the expression pattern of DAZL in humans is somewhat different and is not limited to germ cells. DAZL can be detected in somatic cells of the gonad as well as in later stages of the human preimplantation embryo, long after activation of zygotic gene expression. This suggests that, in contrast to other species, human DAZL may play roles in embryogenesis beyond germ cell development (Cauffman et al. 2005).

Until recently, the molecular basis of DAZL function had not been identified. Using Xenopus laevis oocytes as a model system, Collier et al. (2005) showed that Xdazl, mouse Dazl, human DAZL, human DAZ, and human BOULE all possess the ability to stimulate translation. They also demonstrated that these proteins interact with PABP1 and ePABP. The article by Padmanabhan and Richter (2006) now describes an additional role for DAZL coupled with ePABP in effecting repression or translational activation of the RINGO/Spy mRNA. While the loss of germ cells observed in the mouse DAZL knockout remains to be explained, these exciting findings hint that the DAZ/DAZL/BOULE family of proteins plays additional roles earlier in gametogenesis, likely in a species-specific fashion.

\section{Parallels and prospects}

The evidence discussed above for the roles of specific RNA-binding proteins in regulating waves of translation of maternal mRNAs derives in large part from studies in Xenopus oocytes and embryos. Can we project findings in Xenopus to explain the biology of the gamete in evolutionarily distant species, especially mammals? While we believe the answer is yes, it is important to be vigilant of differences between species (e.g., those discussed in the above section on DAZL).

Indeed, the analysis of mammalian orthologs of genes important for oocyte and early embryo development in model organisms (e.g., Xenopus, Drosophila, C. elegans), even following confirmation of their specific expression in germ cells, can have surprising outcomes. Orthologs of the proteins studied by Padmanabhan and Richter (2006) have been identified in mouse (Cooke et al. 1996; Gebauer and Richter 1996; Spassov and Jurecic 2003b; Cheng et al. 2005; Seli et al. 2005). Studies of CPEB (Tay and Richter 2001) and DAZL (Ruggiu et al. 1997) knockout mice both revealed loss of oocytes prior to meiotic reactivation. This hints at additional functions for these RNA-binding proteins prior to their presumed roles in regulating maternal mRNA translation in mouse oocytes as in Xenopus. Conditional knockout vectors with the potential to manipulate expression at particular stages of oogenesis and embryogenesis may be more useful for delineating the roles of specific proteins in the translational regulation of maternal mRNA expression. Alternatively, knockdown approaches in mouse oocytes using RNAi are also conceivable (Stein et al. 2003).

It is clear that the work of Padmanabhan and Richter (2006), and of others discussed above, sheds new light on our understanding of gamete development, and accumulating evidence suggests that similar proteins and mechanisms are present in developmentally distant species. As indicated by the CPEB and Dazl knockout mice, additional steps that involve the same RNA-binding proteins may occur earlier in the process. It would not be surprising to find that these additional steps are likewise 
organized into translation regulatory cascades. The Xenopus model system, used by Padmanabhan and Richter, will continue to be a powerful tool for studying mechanistic questions that arise from gene deletion approaches in other species.

\section{Acknowledgments}

We thank K. Padmanabhan and J. Richter for their comments and for sharing unpublished information; A. Alexandrov, N. Conrad, N. Kolev, and M. Solomon for critical reading of the manuscript; and Angela Miccinello for secretarial assistance. J.A.S. is an investigator of HHMI and is supported by grant GM26154 from the NIH.

\section{References}

Audic, Y., Omilli, F., and Osborne, H.B. 1997. Postfertilization deadenylation of mRNAs in Xenopus laevis embryos is sufficient to cause their degradation at the blastula stage. Mol. Cell. Biol. 17: 209-218.

Barnard, D.C., Ryan, K., Manley, J.L., and Richter, J.D. 2004. Symplekin and xGLD-2 are required for CPEB-mediated cytoplasmic polyadenylation. Cell 119: 641-651.

Bayaa, M., Booth, R.A., Sheng, Y., and Liu, X.J. 2000. The classical progesterone receptor mediates Xenopus oocyte maturation through a nongenomic mechanism. Proc. Natl. Acad. Sci. 97: 12607-12612.

Bouvet, P., Omilli, F., Arlot-Bonnemains, Y., Legagneux, V., Roghi, C., Bassez, T., and Osborne, H.B. 1994. The deadenylation conferred by the $3^{\prime}$ untranslated region of a developmentally controlled mRNA in Xenopus embryos is switched to polyadenylation by deletion of a short sequence element. Mol. Cell. Biol. 14: 1893-1900.

Braude, P., Bolton, V., and Moore, S. 1988. Human gene expression first occurs between the four- and eight-cell stages of preimplantation development. Nature 332: 459-461.

Brengues, M., Teixeira, D., and Parker, R. 2005. Movement of eukaryotic mRNAs between polysomes and cytoplasmic processing bodies. Science 310: 486-489.

Cao, Q. and Richter, J.D. 2002. Dissolution of the maskin-eIF4E complex by cytoplasmic polyadenylation and poly(A)-binding protein controls cyclin B1 mRNA translation and oocyte maturation. EMBO J. 21: 3852-3862.

Castagnetti, S. and Ephrussi, A. 2003. Orb and a long poly(A) tail are required for efficient oskar translation at the posterior pole of the Drosophila oocyte. Development 130: 835-843.

Castro, A., Peter, M., Lorca, T., and Mandart, E. 2001. c-Mos and cyclin B/cdc2 connections during Xenopus oocyte maturation. Biol. Cell 93: 15-25.

Cauffman, G., Van de Velde, H., Liebaers, I., and Van Steirteghem, A. 2005. DAZL expression in human oocytes, preimplantation embryos and embryonic stem cells. Mol. Hum. Reprod. 11: 405-411.

Chagnovich, D. and Lehmann, R. 2001. Poly(A)-independent regulation of maternal hunchback translation in the Drosophila embryo. Proc. Natl. Acad. Sci. 98: 11359-11364.

Chang, J.S., Tan, L., Wolf, M.R., and Schedl, P. 2001. Functioning of the Drosophila orb gene in gurken mRNA localization and translation. Development 128: 3169-3177.

Cheng, A., Xiong, W., Ferrell Jr., J.E., and Solomon, M.J. 2005. Identification and comparative analysis of multiple mammalian Speedy/Ringo proteins. Cell Cycle 4: 155-165.

Clegg, K.B. and Piko, L. 1982. RNA synthesis and cytoplasmic polyadenylation in the one-cell mouse embryo. Nature 295: $343-344$.
Collier, B., Gorgoni, B., Loveridge, C., Cooke, H.J., and Gray, N.K. 2005. The DAZL family proteins are PABP-binding proteins that regulate translation in germ cells. EMBO $\mathrm{J}$. 24: 2656-2666.

Cooke, H.J., Lee, M., Kerr, S., and Ruggiu, M. 1996. A murine homologue of the human DAZ gene is autosomal and expressed only in male and female gonads. Hum. Mol. Genet. 5: 513-516.

Cosson, B., Couturier, A., Le Guellec, R., Moreau, J., Chabelskaya, S., Zhouravleva, G., and Philippe, M. 2002. Characterization of the poly(A) binding proteins expressed during oogenesis and early development of Xenopus laevis. Biol. Cell 94: 217-231.

Dekel, N. 2005. Cellular, biochemical and molecular mechanisms regulating oocyte maturation. Mol. Cell Endocrinol. 234: 19-25.

de Melo Neto, O.P., Walker, J.A., Martins de Sa, C.M., and Standart, N. 2000. Levels of free PABP are limited by newly polyadenylated mRNA in early Spisula embryogenesis. Nucleic Acids Res. 28: 3346-3353.

de Moor, C.H., Meijer, H., and Lissenden, S. 2005. Mechanisms of translational control by the 3' UTR in development and differentiation. Semin. Cell Dev. Biol. 16: 49-58.

Dickson, K.S., Thompson, S.R., Gray, N.K., and Wickens, M. 2001. Poly(A) polymerase and the regulation of cytoplasmic polyadenylation. J. Biol. Chem. 276: 41810-41816.

Eberhart, C.G., Maines, J.Z., and Wasserman, S.A. 1996. Meiotic cell cycle requirement for a fly homologue of human Deleted in Azoospermia. Nature 381: 783-785.

Eichenlaub-Ritter, U. and Peschke, M. 2002. Expression in invivo and in-vitro growing and maturing oocytes: Focus on regulation of expression at the translational level. Hum. Reprod. Update 8: 21-41.

Faiman, C. and Ryan, R.J. 1967. Serum follicle-stimulating hormone and luteinizing hormone concentrations during the menstrual cycle as determined by radioimmunoassays. $J$. Clin. Endocrinol. Metab. 27: 1711-1716.

Ferby, I., Blazquez, M., Palmer, A., Eritja, R., and Nebreda, A.R. 1999. A novel p34(cdc2)-binding and activating protein that is necessary and sufficient to trigger $\mathrm{G}(2) / \mathrm{M}$ progression in Xenopus oocytes. Genes \& Dev. 13: 2177-2189.

Flach, G., Johnson, M.H., Braude, P.R., Taylor, R.A., and Bolton, V.N. 1982. The transition from maternal to embryonic control in the 2-cell mouse embryo. EMBO J. 1: 681-686.

Fox, M., Urano, J., and Reijo Pera, R.A. 2005. Identification and characterization of RNA sequences to which human PUMILIO-2 (PUM2) and deleted in Azoospermia-like (DAZL) bind. Genomics 85: 92-105.

Gandolfi, T.A. and Gandolfi, F. 2001. The maternal legacy to the embryo: Cytoplasmic components and their effects on early development. Theriogenology 55: 1255-1276.

Gebauer, F. and Richter, J.D. 1996. Mouse cytoplasmic polyadenylylation element binding protein: An evolutionarily conserved protein that interacts with the cytoplasmic polyadenylylation elements of c-mos mRNA. Proc. Nat1. Acad. Sci. 93: 14602-14607.

Gebauer, F., Xu, W., Cooper, G.M., and Richter, J.D. 1994. Translational control by cytoplasmic polyadenylation of cmos mRNA is necessary for oocyte maturation in the mouse. $E M B O$ I. 13: 5712.

Gray, N.K. and Wickens, M. 1998. Control of translation initiation in animals. Annu. Rev. Cell Dev. Biol. 14: 399-458.

Groisman, I., Huang, Y.S., Mendez, R., Cao, Q., Theurkauf, W., and Richter, J.D. 2000. CPEB, maskin, and cyclin B1 mRNA at the mitotic apparatus: Implications for local translational control of cell division. Cell 103: 435-447. 
Groisman, I., Jung, M.Y., Sarkissian, M., Cao, Q., and Richter, J.D. 2002. Translational control of the embryonic cell cycle. Cell 109: 473-483.

Gu, W., Deng, Y., Zenklusen, D., and Singer, R.H. 2004. A new yeast PUF family protein, Puf6p, represses ASH1 mRNA translation and is required for its localization. Genes \& Dev. 18: $1452-1465$.

Houston, D.W. and King, M.L. 2000. A critical role for Xdazl, a germ plasm-localized RNA, in the differentiation of primordial germ cells in Xenopus. Development 127: 447-456.

Huang, Y.S., Carson, J.H., Barbarese, E., and Richter, J.D. 2003. Facilitation of dendritic mRNA transport by CPEB. Genes \& Dev. 17: 638-653.

Huarte, J., Stutz, A., O'Connell, M.L., Gubler, P., Belin, D., Darrow, A.L., Strickland, S., and Vassalli, J.D. 1992. Transient translational silencing by reversible mRNA deadenylation. Cell 69: 1021-1030.

Jackson, R.J. and Standart, N. 1990. Do the poly(A) tail and 3' untranslated region control mRNA translation? Cell 62: 1524.

Jiao, X., Trifillis, P., and Kiledjian, M. 2002. Identification of target messenger RNA substrates for the murine deleted in azoospermia-like RNA-binding protein. Biol. Reprod. 66: 475485.

Karashima, T., Sugimoto, A., and Yamamoto, M. 2000. Caenorhabditis elegans homologue of the human azoospermia factor DAZ is required for oogenesis but not for spermatogenesis. Development 127: 1069-1079.

Kedersha, N., Stoecklin, G., Ayodele, M., Yacono, P., LykkeAndersen, J., Fitzler, M.J., Scheuner, D., Kaufman, R.J., Golan, D.E., and Anderson, P. 2005. Stress granules and processing bodies are dynamically linked sites of mRNP remodeling. J. Cell Biol. 169: 871-884.

Kuhn, U. and Wahle, E. 2004. Structure and function of poly(A) binding proteins. Biochim. Biophys. Acta 1678: 67-84.

LaMarca, M.J., Smith, L.D., and Strobel, M.C. 1973. Quantitative and qualitative analysis of RNA synthesis in stage 6 and stage 4 oocytes of Xenopus laevis. Dev. Biol. 34: 106-118.

Lenormand, J.L., Dellinger, R.W., Knudsen, K.E., Subramani, S., and Donoghue, D.J. 1999. Speedy: A novel cell cycle regulator of the G2/M transition. EMBO J. 18: 1869-1877.

Maegawa, S., Yamashita, M., Yasuda, K., and Inoue, K. 2002. Zebrafish DAZ-like protein controls translation via the sequence 'GUUC.' Genes Cells 7: 971-984.

Mangus, D.A., Evans, M.C., and Jacobson, A. 2003. Poly(A)binding proteins: Multifunctional scaffolds for the post-transcriptional control of gene expression. Genome Biol. 4: 223.

Manley, J.L. 1995. A complex protein assembly catalyzes polyadenylation of mRNA precursors. Curr. Opin. Genet. Dev. 5: 222-228.

Matova, N. and Cooley, L. 2001. Comparative aspects of animal oogenesis. Dev. Biol. 231: 291-320.

Mendez, R. and Richter, J.D. 2001. Translational control by CPEB: A means to the end. Nat. Rev. Mol. Cell Biol. 2: 521529.

Mendez, R., Hake, L.E., Andresson, T., Littlepage, L.E., Ruderman, J.V., and Richter, J.D. 2000. Phosphorylation of CPE binding factor by Eg2 regulates translation of c-mos mRNA. Nature 404: 302-307.

Moore, M. 2005. From birth to death: The complex lives of eukaryotic mRNAs. Science 309: 1514-1518.

Moore, F.L., Jaruzelska, J., Fox, M.S., Urano, J., Firpo, M.T., Turek, P.J., Dorfman, D.M., and Pera, R.A. 2003. Human Pumilio-2 is expressed in embryonic stem cells and germ cells and interacts with DAZ (Deleted in AZoospermia) and DAZ-like proteins. Proc. Natl. Acad. Sci. 100: 538-543.
Nakahata, S., Kotani, T., Mita, K., Kawasaki, T., Katsu, Y., Nagahama, Y., and Yamashita, M. 2003. Involvement of Xenopus Pumilio in the translational regulation that is specific to cyclin B1 mRNA during oocyte maturation. Mech. Dev. 120: 865-880.

Newport, J. and Kirschner, M. 1982a. A major developmental transition in early Xenopus embryos: I. Characterization and timing of cellular changes at the midblastula stage. Cell 30: 675-686.

- 1982b. A major developmental transition in early Xenopus embryos: II. Control of the onset of transcription. Cell 30: 687-696.

Oh, B., Hwang, S., McLaughlin, J., Solter, D., and Knowles, B.B. 2000. Timely translation during the mouse oocyte-to-embryo transition. Development 127: 3795-3803.

Padmanabhan, K. and Richter, J.D. 2006. Regulated Pumilio-2 binding controls RINGO/Spy mRNA translation and CPEB activation. Genes \& Dev. (this issue).

Paynton, B.V. and Bachvarova, R. 1994. Polyadenylation and deadenylation of maternal mRNAs during oocyte growth and maturation in the mouse. Mol. Reprod. Dev. 37: 172180.

Piccioni, F., Zappavigna, V., and Verrotti, A.C. 2005. Translational regulation during oogenesis and early development: The cap-poly(A) tail relationship. C. R. Biol. 328: 863-881.

Rao, A.J., Moudgal, N.R., Raj, H.G., Lipner, H., and Greep, R.O. 1974. The role of FSH and LH in the initiation of ovulation in rats and hamsters: A study using rabbit antisera to ovine FSH and LH. J. Reproduc. Fertility 37: 323-330.

Richter, J.D. 1999. Cytoplasmic polyadenylation in development and beyond. Microbiol. Mol. Biol. Rev. 63: 446-456.

Rodman, T.C. and Bachvarova, R. 1976. RNA synthesis in preovulatory mouse oocytes. J. Cell Biol. 70: 251-257.

Rouhana, L., Wang, L., Buter, N., Kwak, J.E., Schiltz, C.A., Gonzalez, T., Kelley, A.E., Landry, C.F., and Wickens, M. 2005. Vertebrate GLD2 poly(A) polymerases in the germline and the brain. RNA 11: 1117-1130.

Ruggiu, M., Speed, R., Taggart, M., McKay, S.J., Kilanowski, F., Saunders, P., Dorin, J., and Cooke, H.J. 1997. The mouse Dazla gene encodes a cytoplasmic protein essential for gametogenesis. Nature 389: 73-77.

Sagata, N. 1996. Meiotic metaphase arrest in animal oocytes: Its mechanisms and biological significance. Trends Cell Biol. 6: 22-28.

Saunders, P.T., Turner, J.M., Ruggiu, M., Taggart, M., Burgoyne, P.S., Elliott, D., and Cooke, H.J. 2003. Absence of $\mathrm{mDazl}$ produces a final block on germ cell development at meiosis. Reproduction 126: 589-597.

Seli, E., Lalioti, M.D., Flaherty, S.M., Sakkas, D., Terzi, N., and Steitz, J.A. 2005. An embryonic poly(A)-binding protein $(\mathrm{ePAB})$ is expressed in mouse oocytes and early preimplantation embryos. Proc. Nat1. Acad. Sci. 102: 367-372.

Spassov, D.S. and Jurecic, R. 2003a. Mouse Pum1 and Pum2 genes, members of the Pumilio family of RNA-binding proteins, show differential expression in fetal and adult hematopoietic stem cells and progenitors. Blood Cells Mol. Dis. 30: 55-69.

- 2003b. The PUF family of RNA-binding proteins: Does evolutionarily conserved structure equal conserved function? IUBMB Life 55: 359-366.

Stebbins-Boaz, B. and Richter, J.D. 1994. Multiple sequence elements and a maternal mRNA product control cdk2 RNA polyadenylation and translation during early Xenopus development. Mol. Cell. Biol. 14: 5870-5880.

Stebbins-Boaz, B., Hake, L.E., and Richter, J.D. 1996. CPEB controls the cytoplasmic polyadenylation of cyclin, Cdk2 and 
Vasudevan et al.

c-mos mRNAs and is necessary for oocyte maturation in Xenopus. EMBO I. 15: 2582-2592.

Stein, P., Svoboda, P., and Schultz, R.M. 2003. Transgenic RNAi in mouse oocytes: A simple and fast approach to study gene function. Dev. Biol. 256: 187-193.

Tay, J. and Richter, J.D. 2001. Germ cell differentiation and synaptonemal complex formation are disrupted in CPEB knockout mice. Dev. Cell 1: 201-213.

Terret, M.E., Ferby, I., Nebreda, A.R., and Verlhac, M.H. 2001. RINGO efficiently triggers meiosis resumption in mouse oocytes and induces cell cycle arrest in embryos. Biol. Cell 93: 89-97.

Tian, J., Kim, S., Heilig, E., and Ruderman, J.V. 2000. Identification of XPR-1, a progesterone receptor required for Xenopus oocyte activation. Proc. Natl. Acad. Sci. 97: 1435814363.

Uto, K. and Sagata, N. 2000. Nek2B, a novel maternal form of Nek2 kinase, is essential for the assembly or maintenance of centrosomes in early Xenopus embryos. EMBO J. 19: 18161826.

Voeltz, G.K. and Steitz, J.A. 1998. AUUUA sequences direct mRNA deadenylation uncoupled from decay during Xenopus early development. Mol. Cell. Biol. 18: 7537-7545.

Voeltz, G.K., Ongkasuwan, J., Standart, N., and Steitz, J.A. 2001. A novel embryonic poly(A) binding protein, ePAB, regulates mRNA deadenylation in Xenopus egg extracts. Genes \& Dev. 15: 774-788.

Wahle, E. 1995. 3'-End cleavage and polyadenylation of mRNA precursors. Biochim. Biophys. Acta 1261: 183-194.

Wharton, R.P., Sonoda, J., Lee, T., Patterson, M., and Murata, Y. 1998. The Pumilio RNA-binding domain is also a translational regulator. Mol. Cell 1: 863-872.

White, E.K., Moore-Jarrett, T., and Ruley, H.E. 2001. PUM2, a novel murine puf protein, and its consensus RNA-binding site. RNA 7: 1855-1866.

Wickens, M. 1990. In the beginning is the end: Regulation of poly(A) addition and removal during early development. Trends Biochem. Sci. 15: 320-324.

Wickens, M., Bernstein, D.S., Kimble, J., and Parker, R. 2002. A PUF family portrait: $3^{\prime} \mathrm{UTR}$ regulation as a way of life. Trends Genet. 18: 150-157.

Wilczynska, A., Aigueperse, C., Kress, M., Dautry, F., and Weil, D. 2005. The translational regulator CPEB1 provides a link between dcp1 bodies and stress granules. J. Cell Sci. 118 (Pt 5): 981-992.

Wilkie, G.S., Gautier, P., Lawson, D., and Gray, N.K. 2005. Embryonic poly(A)-binding protein stimulates translation in germ cells. Mol. Cell. Biol. 25: 2060-2071.

Wormington, M. 1993. Poly(A) and translation: Development control. Curr. Opin. Cell Biol. 5: 950-954.

Wormington, M., Searfoss, A.M., and Hurney, C.A. 1996. Overexpression of poly(A) binding protein prevents maturationspecific deadenylation and translational inactivation in Xenopus oocytes. EMBO J. 15: 900-909.

Xu, E.Y., Moore, F.L., and Pera, R.A. 2001. A gene family required for human germ cell development evolved from an ancient meiotic gene conserved in metazoans. Proc. Natl. Acad. Sci. 98: 7414-7419.

Zamore, P.D., Williamson, J.R., and Lehmann, R. 1997. The Pumilio protein binds RNA through a conserved domain that defines a new class of RNA-binding proteins. RNA 3: $1421-1433$. 


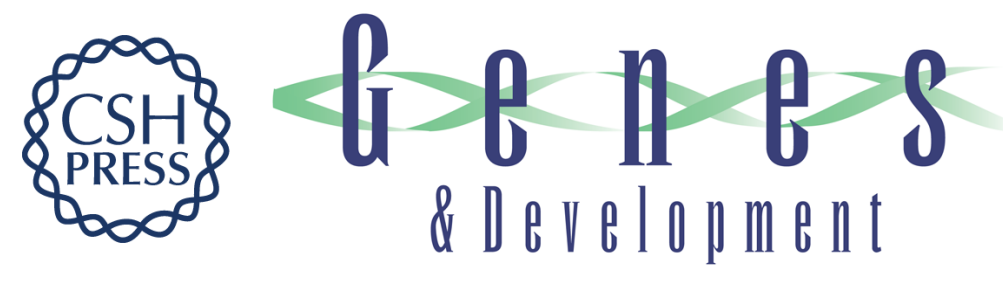

\section{Metazoan oocyte and early embryo development program: a progression through translation regulatory cascades}

Shobha Vasudevan, Emre Seli and Joan A. Steitz

Genes Dev. 2006, 20:

Access the most recent version at doi:10.1101/gad.1398906

\section{Related Content Regulated Pumilio-2 binding controls RINGO/Spy mRNA translation and CPEB activation \\ Kiran Padmanabhan and Joel D. Richter \\ Genes Dev. January, 2006 20: 199-209}

References This article cites 88 articles, 34 of which can be accessed free at:

http://genesdev.cshlp.org/content/20/2/138.full.htmI\#ref-list-1

Articles cited in:

http://genesdev.cshlp.org/content/20/2/138.full.html\#related-urls

\section{License}

Email Alerting

Service

Receive free email alerts when new articles cite this article - sign up in the box at the top right corner of the article or click here.

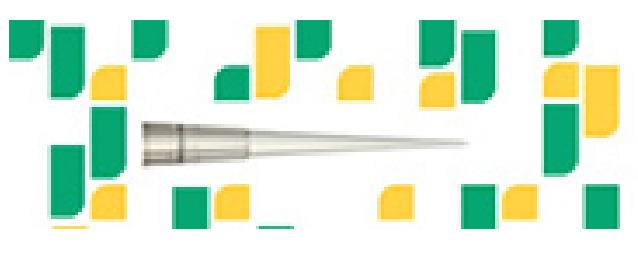

Focused on your science. 